DOI:10.5216/cab.v11i3.7012

\title{
BIOPSIAS LUTEAIS EM VACAS NELORE
}

\author{
Ian Martin, ${ }^{1}$ Caroline Junko Fujihara, ${ }^{2}$ Wolff Camargo Marques Filho, ${ }^{3}$ Rosiara Rosárias Dias \\ Maziero, ${ }^{4}$ Carmo Emanuel Almeida Biscarde ${ }^{5}$ e João Carlos Pinheiro Ferreira ${ }^{6}$
}

1. Aluno de pós-doutorado, Departamento de Reprodução Animal e Radiologia Veterinária, Faculdade de Medicina Veterinaria e Zootecnia, Unesp, Campus de Botucatu. E-mail: ianmartin@uol.com.br 2. Aluna de doutorado, Departamento de Reprodução Animal e Radiologia Veterinária, Faculdade de Medicina Veterinaria e Zootecnia (FMVZ), Unesp, Campus de Botucatu 3. Aluno de doutorado, Departamento de Reprodução Animal e Radiologia Veterinária, FMVZ, Unesp, Campus de Botucatu 4. Aluna de mestrado, Departamento de Reprodução Animal e Radiologia Veterinária, FMVZ, Unesp, Campus de Botucatu 5. Aluno de mestrado, Departamento de Reprodução Animal e Radiologia Veterinária, FMVZ, Unesp, Campus de Botucatu 6. Professor adjunto, Departamento de Reprodução Animal e Radiologia Veterinária, FMVZ, Unesp, Campus de Botucatu.

\section{RESUMO}

O presente estudo descreve uma técnica para obtenção de fragmentos luteais empregando-se a colpotomia. Os animais foram submetidos à anestesia epidural e no fórnix vaginal e, após dez minutos, realizou-se uma incisão no fundo vaginal com lâmina de bisturi, bem como procedeu-se à dissecção do tecido, até que fossem possíveis o acesso à cavidade pélvica e a tração dos ovários para o interior vaginal. Realizou-se, então, a colheita de biopsia luteínica, com o auxílio de uma pinça do tipo Yomann. Sinais de dor e estresse foram observados apenas em duas colheitas durante a incisão no fundo vaginal, a tração do ovário ou durante a biopsia luteínica. Contudo, esses sinais foram observados em dez colheitas durante a dissecção da parede vaginal e peritôneo. Registrou-se a ocorrência de ataxia em $38,81 \%$ colheitas, a qual esteve relaciona$\mathrm{da}$, normalmente, a um procedimento mais longo. As ataxias podem ser divididas em leve (15/26), moderada (6/26) e severa (5/26). A avaliação da presença de adesões ovarianas ipsilaterais à incisão realizou-se apenas até a quarta colheita, sendo notadas em dezesseis colheitas. O protocolo empregado mostrou-se um método seguro e eficiente na obtenção de fragmentos luteais. A baixa incidência de aderências permite o uso consecutivo das fêmeas sem interferência nas ovulações e colheitas subsequentes.

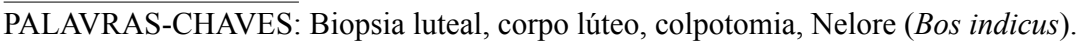

\section{ABSTRACT}

\section{LUTEAL BIOPSY IN NELLORE COWS}

The present study describes a technique to obtain consecutive luteal samples by colpotomy. The animals received an epidural anesthesia and local anesthesia (vaginal vault) and after ten minutes the vaginal vault was incised with a scalpel blade and tissue was dissected to provide access to the pelvic cavity and to retract the ovary into the vagina. Then, a luteal biopsy was performed with a Yomann biopsy nipper. Signs indicative of pain and stress during the vaginal vault incision, traction of ovary or luteal biopsy were observed only in two collections. However, these signs were observed in ten collections during dissection of the vaginal wall and peritoneum. The occurrence of ataxia was observed in 26 collections and it was usually related to a longer duration of the procedure. Ataxia could be divided in light (15/26), moderate (6/26) and severe (5/26). The occurrence of ovarian adhesions ipsilateral to the incision was evaluated only in the initial four collections. Adhesions were present in 16 collections. The protocol described above provided a safe and efficient method to acquire luteal samples. The low incidence of adhesions allows the consecutive use of females without any interference in subsequent ovulations and collections.

KEYWORDS: Colpotomy, corpus luteum, luteal biopsy, Nellore (Bos indicus). 


\section{INTRODUÇÃO}

Diversos pesquisadores vêm empregando a colheita de fragmentos luteais para o estudo da fisiologia do corpo lúteo (VAN DEN BROECK et al., 2002a; VAN DEN BROECK et al., 2002b; D'HAESELEER et al., 2006a; D'HAESELEER et al., 2006b; D'HAESELEER et al., 2007). Contudo, a maioria dos estudos é realizada com fragmentos de ovários provenientes de abatedouro, para os quais a fase do ciclo estral é determinada de acordo com o desenvolvimento folicular, características morfológicas do corpo lúteo e atividade secretora do trato genital feminino (IRELAND et al., 1980).

A partir desses achados foram determinadas quatro fases do ciclo estral, a saber: fase $\mathrm{I}\left(1^{\circ}-4^{\circ} \mathrm{dia}\right)$, fase II $\left(5^{\circ}-10^{\circ}\right)$, fase III $\left(11^{\circ}-17^{\circ}\right)$ e fase IV $\left(18^{\circ}-20^{\circ}\right)$. Quando se empregou essa classificação em animas com o dia do ciclo estral conhecido, a fase do ciclo estral foi determinada corretamente, com erro de mais ou menos um dia, em $70 \%$ dos animais e, incorretamente, nos demais (30\%; IRELAND et al., 1980).

Portanto, considerando-se que alguns eventos fisiológicos do ciclo estral ocorrem em curtos períodos de tempo, tais como a ovulação e a luteólise, a classificação morfológica pode gerar erros importantes, como, por exemplo, classificar uma fase como proestro quando ainda existem elevadas concentrações plasmáticas de progesterona.

Como método alternativo, KOT et al. (1999) relataram a colheita de biopsias luteais guiadas pela ultrassonografia transretal, em dias conhecidos do ciclo estral, empregando agulhas do tipo Tru-cut ${ }^{\circledR}$, acopladas a uma guia de aspiração folicular. Contudo, tal técnica apresenta como limitações o elevado custo dos equipamentos necessários e a dificuldade de obtenção das agulhas.

Outros investigadores têm empregado a colpotomia (incisão no fundo vaginal) para a realização de ovariectomia (DROST et al., 1992; CASSAR et al., 2002; JO et al., 2002; SILVA et al., 2004; KLIEM et al., 2008). Porém essa técnica impossibilita a reutilização dessa fêmea para fins reprodutivos, quando bilateral, ou restringe o seu uso a apenas duas colheitas, uma de cada ovário.

O objetivo do presente estudo foi descrever uma técnica para obtenção de fragmentos luteais consecuti- vos, empregando-se a colpotomia, sem comprometer a função ovariana em fêmeas da raça Nelore.

\section{MATERIAL E MÉTODOS}

Utilizaram-se dezesseis vacas Nelore Puro de Origem (P.O.), adultas (primíparas e pluríparas), com escore corporal igual ou superior a 3 (escala de 0 a 5; HOUGHTON et al., 1990), apresentando atividade ovariana cíclica e período pós-parto superior a sessenta dias, provenientes dos rebanhos das Fazendas Experimentais São Manuel e Edigárdia da Faculdade de Medicina Veterinária e Zootecnia (Unesp), Campus de Botucatu. Os animais foram alocados em baias descobertas, trinta dias antes do início do estudo, e durante todo o período em que permaneceram estabulados receberam uma dieta balanceada contendo feno de coast-cross, bagaço de cana, milho, farelo de soja e concentrado e água à vontade.

Após o período de adaptação de trinta dias às condições experimentais, submeteram-se os animais à sincronização do estro com um análogo de GnRH (50 $\mu \mathrm{g}$ de lecirelina, Gestran Plus $\left.{ }^{\circledR}{ }^{1}, \mathrm{IM}\right)$ e colocação de um implante intravaginal de progesterona $\left(\operatorname{Primer}{ }^{\circledR}{ }^{2}\right.$ ), o qual foi mantido por sete dias. Nos dias 6 e 7 , administraram-se 5,0 mg e 2,5 mg de cloprostenol (Sincrosin $\left.\AA^{3}, I M\right)$, respectivamente. Posteriormente, as fêmeas foram acompanhadas por ultrassonografia transretal (Aloka ${ }^{4}$ SSD 500 com transdutor de 5,0 $\mathrm{MHz})$ até que a ovulação fosse detectada $(\mathrm{D} 1=$ dia um do ciclo estral).

Os animais sincronizados foram submetidos às colheitas de fragmentos luteais em dias prédeterminados do ciclo estral (D6, D10, D15, D18 e 24 horas após a detecção das concentrações plasmáticas de progesterona abaixo de $1 \mathrm{ng} / \mathrm{mL}$ - pósluteólise), em cinco ciclos estrais consecutivos. Após cada colheita, realizou-se a administração de $\mathrm{PGF}_{2 \alpha}$ e os animais foram ressincronizados, de modo a permitir o desenvolvimento de outra colheita no ciclo subsequente (intervalo médio ao redor de um mês).

\footnotetext{
1. Gestran Plus, Tecnopec Ltda., São Paulo, Brasil.

2. Primer, Tecnopec Ltda., São Paulo, Brasil.

3. Sincrosin, Vallee S.A., São Paulo, Brasil.

4. Aloka Co. Ltda., Tokyo, Japan.
} 
Antes de cada colheita, os ovários de cada fêmea foram avaliadas por ultrassonografia transretal para caracterização do corpo lúteo (CL) e a região perineal higienizada com água corrente, sabão e solução de Kilol ${ }^{\circledR 5}$ na diluição de 1:250 mL.

Anteriormente ao procedimento de colheita das amostras luteais, empregou-se o seguinte protocolo anestésico: anestesia epidural, combinando os anestésicos cloridrato de lidocaina $2 \%$ (Xylestesin ${ }^{\circledR}{ }^{6} 2 \%$ ), na dose média de $0,14 \mathrm{mg} / \mathrm{kg}$ (de 0,10 a $0,18 \mathrm{mg} / \mathrm{kg}$ ), e cloridrato de xilazina (Rompum ${ }^{\circledR}{ }_{-}{ }^{7}$ ), na dose média de $0,017 \mathrm{mg} / \mathrm{kg}$ (de 0,029 a $0,009 \mathrm{mg} / \mathrm{kg}$ ). Adicionalmente, desenvolveu-se um bloqueio local no fórnix vaginal com 15 a $20 \mathrm{~mL}$ de cloridrato de lidocaína $2 \%$ com o auxílio de um equipo acoplado a uma seringa de $20 \mathrm{~mL}$ (Figura 1).

Dez minutos após o procedimento anestésico, procedeu-se a uma incisão de aproximadamente oito centímetros de comprimento, na região dorsolateral no fórnix vaginal ipsilateral ao ovário que continha o corpo lúteo, com uma lâmina de bisturi acoplada a um estilete de uso comum, que permitia a retração da extremidade e superfície cortante durante a introdução no vestíbulo vaginal (Figura 1). O procedimento permitia, sem grandes dificuldades, $o$ acesso à cavidade pélvica. Contudo, em algumas fêmeas, foi necessária maior divulsão do tecido submucoso, muscular e peritôneo.

Após a incisão no fórnix, introduziu-se a mão na cavidade pélvica e localizava-se o ovário, que foi tracionado até o interior da vagina, de modo a permitir a colheita de fragmentos luteais com o auxílio de uma pinça do tipo Yomann ("boca de jacaré"), que possuía uma cavidade de $1,0 \times 0,3 \times 0,4 \mathrm{~cm}$ (comprimento $\mathrm{x}$ largura $\mathrm{x}$ altura).

No pós-operatório foram empregados, por via intramuscular, penicilina benzatina $(15.000 \mathrm{UI} / \mathrm{kg}$

5. Kilol, Quinabra, São José dos Campos, SP, Brasil.

6. Xylestesin, Cristália Ltda., Itapira, SP, Brasil.

7. Rompum, Bayer S.A., São Paulo, SP, Brasil. de peso vivo; Septipen ${ }^{\circledR}{ }^{8}$ ) e flunixin meglumine ${ }^{9}$ na dose de $2,2 \mathrm{mg} / \mathrm{kg}$.

As pinças empregadas no presente estudo foram lavadas após cada uso em água corrente e sabão neutro e, posteriormente, mantidas em solução de Kilol ${ }^{\circledR}$, na diluição de 1:250 mL, até o uso subsequente. Ao final de cada dia, lavaram-se as pinças novamente em água corrente e sabão, sendo secas em estufa convencional e mantidas embrulhadas em um campo cirúrgico.

Os fragmentos obtidos foram retirados da pinça com auxílio de uma agulha, lavados em solução fisiológica e acondicionados para posterior uso em técnicas de imunoistoquímica e RT-PCR. Adicionalmente realizou-se a coloração de hematoxilina-eosina para avaliação das características histológicas do corpo lúteo bovino ao longo do ciclo estral (Figura 2).

Este estudo foi aprovado pela Comissão de Ética no Uso de Animais da Faculdade de Medicina Veterinária e Zootecnia da Universidade Estadual Paulista "Julio de Mesquita Filho," Campus de Botucatu.

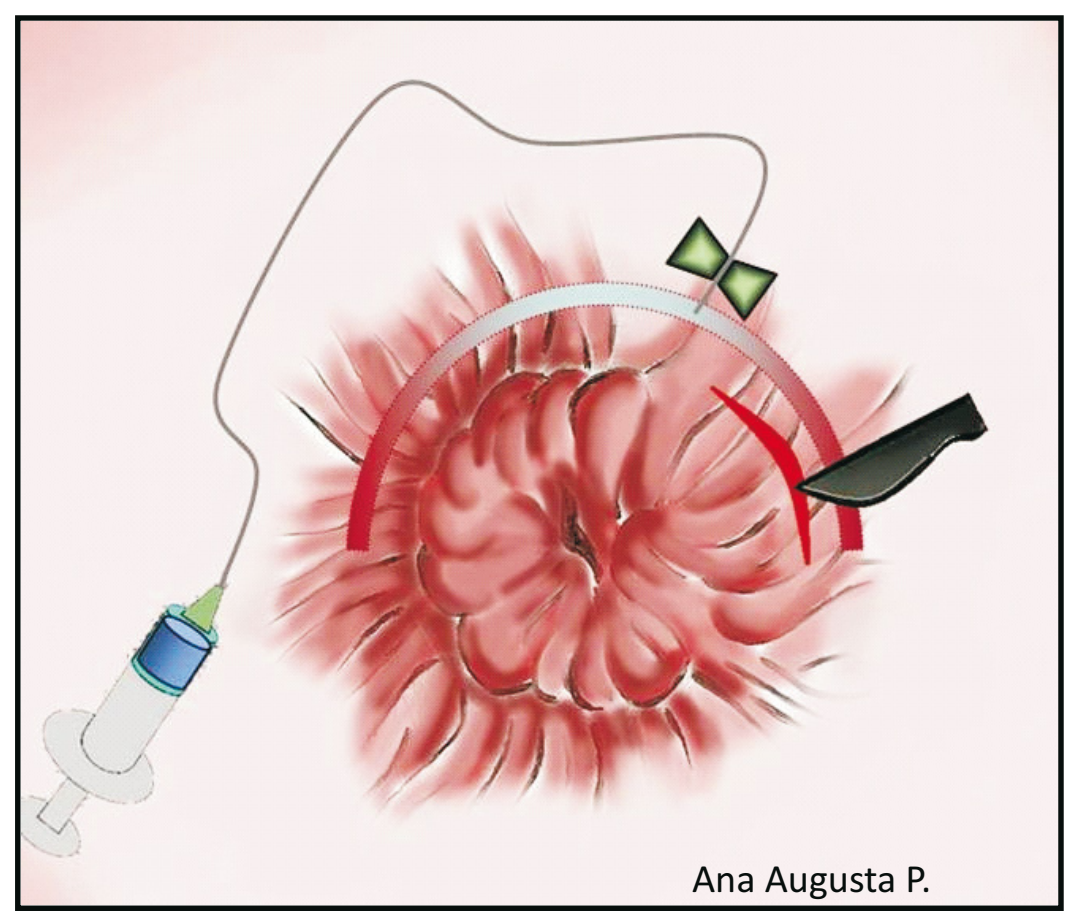

FIGURA 1. Esquema do procedimento anestésico local utilizado (arco acima do cérvix) e local da incisão.
8. Septipen, Vallee S.A., São Paulo, SP, Brasil.

9. Flunixin Injetável, Chemitec, São Paulo, SP, Brasil. 

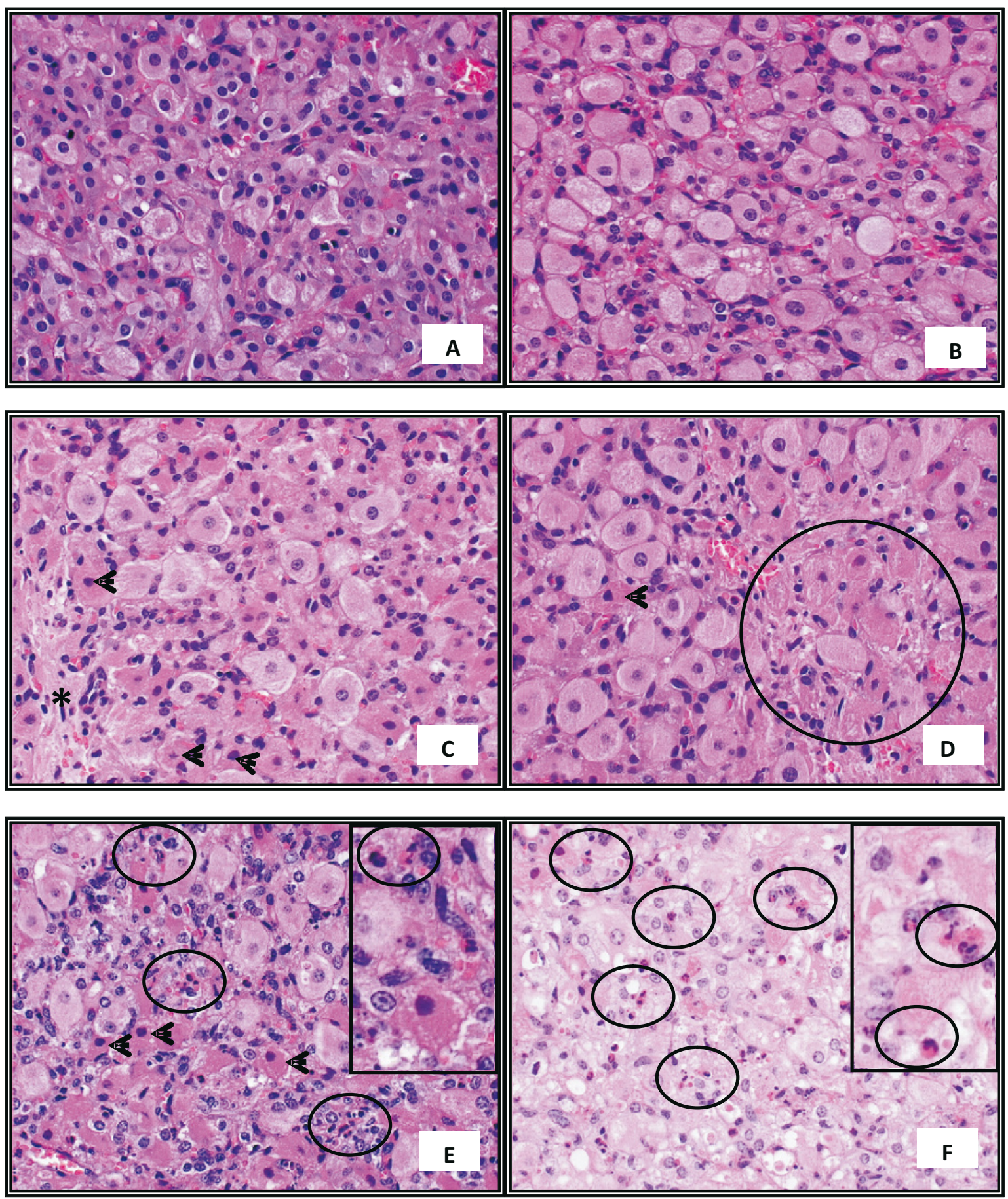

FIGURA 2. Corpo lúteo de vacas Nelore (Bos taurus indicus) nos dias 6 (A), 10 (B), 15 (C), 18 (D), 18L (E) e após a luteólise - LUT (F). HE. A) Dia 6 do ciclo estral - células luteais grandes de menor tamanho em comparação ao dia 10 do ciclo, citoplasma vacuolado. B) Células luteias grandes com citoplasma amplo, de coloração rósea clara, alguns vacuolados. Presença de células luteais pequenas e vasos sanguíneos com hemácias no interior. C) Trabéculas de estroma (*). Células luteais grandes com citoplasma amplo, mais eosinofílico, alguns vacuolados e presença de núcleos condensados (setas). D) Agrupado de células com citoplasma eosinofílico, núcleos condensados (círculo). Presença de células com esse mesmo aspecto, isoladas (seta). Demais células luteias grandes com citoplasma amplo, eosinofílico e núcleo central. E) Presença de numerosos cospúsculos apoptóticos (círculos), células luteais grandes de tamanho menor que nos demais dias do ciclo, com citoplasma de intensa eosinofilia e núcleos condensados (seta). Detalhe: maior aumento da presença de corpúsculos apoptóticos. F) Luteólise. Idem E, porém com maior número de cospúsculos apoptóticos (círculos). Coloração hematoxilina-eosina, aumento 400X. 


\section{RESULTADOS E DISCUSSÃO}

A técnica descrita para biopsia luteal se mostrou viável, com a obtenção de fragmentos satisfatórios em todos os animais submetidos ao procedimento. Contudo, em função de algumas falhas de ovulação durante a sincronização do ciclo, foram realizadas sessenta e sete colheitas, ao invés das oitenta inicialmente previstas. As amostras luteais obtidas mostraram-se adequadas para os fins pretendidos, como a avaliação histológica pela coloração de hematoxilina-eosina (Figura 2), reações de imunoistoquímica e extração de RNA.

Após a sincronização subsequente, procedeuse à avaliação diária das fêmeas por meio de ultrassonografia transretal, para verificar a ocorrência da ovulação. Nesse período, foi possível observar a presença de muco vaginal com estrias de pus em 18,52\% (10/54) das fêmeas. Assinale-se que essas vacas estavam com um implante vaginal, o que pode ter facilitado a ocorrência de vaginites.

O protocolo anestésico empregado no presente estudo foi semelhante ao descrito por LEE et al. (2004) em fêmeas holandesas. Tais autores observaram boa sedação e possibilidade de executar uma laparotomia com o emprego de $0,25 \mathrm{mg} / \mathrm{kg}$ de cloridrato de xilazina associado a $0,10 \mathrm{mg} / \mathrm{kg}$ de cloridrato de lidocaína no espaço epidural. No presente estudo, foi inicialmente empregada a dose descrita para as fêmeas holandesas. Contudo, como os animais apresentaram intensa ataxia após o procedimento, houve a necessidade de diminuir a dose de cloridrato de xilazina preconizada, adaptando-a às fêmeas Nelore, que se mostraram mais susceptíveis a esse fármaco.

Assim, a dose de cloridrato de xilazina empregada no presente estudo é bem inferior àquela descrita na literatura $(0,05 \mathrm{mg} / \mathrm{kg}, \mathrm{CARON} \& \mathrm{LEBLANC}$ et al., 1989; ST JEAN et al., 1990; 0,07 mg/kg, CAULKETT et al., 1993).

A anestesia empregada neste estudo permitiu a colheita das biopsias luteais com as fêmeas permanecendo em estação durante todo o procedimento. Para que as fêmeas com sinais de ataxia permanecessem em estação, foram empregadas cintas, presas ao tronco de contenção, ao redor dos membros anteriores e posteriores. Esse procedimento resultou em sinais de dor e estresse (vocalização, sialorreia, inquietação e comportamento de fuga) observados em apenas $2,99 \%$
(2/67) das colheitas durante a incisão no fundo vaginal, a tração do ovário ou durante a biopsia luteínica e em 14,93\% (10/67) das colheitas durante a dissecção da parede vaginal e peritôneo. Durante o estudo, notouse que o procedimento de divulsão da parede vaginal aumentava o desconforto da fêmea. Por isso, optou-se por uma incisão maior no fundo vaginal, com menor necessidade de divulsão da parede.

A ocorrência de ataxia foi observada em 38,81\% (26/67) das colheitas, e geralmente estava relacionada com os procedimentos mais demorados e não aos sinais de dor ou a dose empregada na anestesia, uma vez que a redução da dose de cloridrato de xilazina não suprimiu a ocorrência de ataxia. A maioria dos episódios de ataxia observados $(57,69 \%$ - 15/26) foi leve. A ocorrência de ataxia moderada ou severa foi visualizada em apenas $23,08 \%$ (6/26) e 19,23\% (5/26) das colheitas, respectivamente. Esses resultados diferem dos encontrados por St JEAN et al. (1990), que relataram $75 \%(6 / 8)$ de ataxia moderada nas fêmeas estudadas, e dos citados por CARON \& LEBLANC et al. (1989), que mencionaram alta taxa de ataxia moderada. Já CAULKETT et al. (1993) observaram $27,6 \%$ de ataxia, variando de leve a moderada, taxa semelhante à registrada no presente estudo.

De forma contrária, HIRAOKA et al. (2007) relataram a ocorrência de ataxia em apenas $1,12 \%$ (1/90) dos animais, mas 5,56\% (5/90) dos animais permaneceram em decúbito esternal durante ou após o procedimento cirúrgico. Adicionalmente, neste estudo $7,69 \%$ (2/26) das fêmeas que apresentaram ataxia tiveram dificuldade em permanecer em estação após o procedimento, o que foi relatado por HIRAOKA et al. (2007), mas não por ST JEAN et al. (1990).

Quanto ao procedimento cirúrgico empregado no presente estudo, foi observada aderência ovariana ipsilateral à incisão em 25,93\% (14/54) das fêmeas, sem que essa acarretasse o comprometimento das ovulações e biopsias subsequentes. Observe-se que essa avaliação foi feita apenas até a quarta colheita. Porcentagem maior foi observada por DROST et al. (1992), que relataram aderência ipsilateral em três animais, adesão generalizada em uma vaca após primeira incisão e em duas vacas após duas incisões $(35,29 \% ; 6 / 17)$. Esses autores também mencionaram dificuldades na localização da incisão quando esta era realizada com o emprego de um pequeno trocater 
ou uma tesoura, o que não foi verificado no presente estudo. O emprego da incisão com a lâmina de bisturi permitiu a obtenção de um orifício de fácil localização e de tamanho suficiente para a recuperação do ovário até o canal vaginal.

Assim como descrito por DROST et al. (1992), não foi verificada a ocorrência de anorexia ou qualquer alteração sistêmica nos animais empregados no presente estudo, e também não se notou a ocorrência de perfuração intestinal ou da bexiga, assim como suposto por SILVA et al. (2004). Neste estudo, verificou-se a ocorrência de vaginite em 14,63\% (10/67) das fêmeas, com a presença de muco purulento em apenas em três $(4,48 \% ; 3 / 67)$. Deve-se considerar, neste caso, a possibilidade de a contaminação e/ou irritação advir do implante intravaginal.

SILVA et al. (2004) compararam a via vaginal (colpotomia) com o flanco para o acesso ao ovário e concluíram que a via vaginal requer mais tempo, maior experiência do técnico, causa maior desconforto ao animal, além de ser desconfortável ao cirurgião. Contudo, é a que apresenta menos complicações pós-operatórias. No presente estudo, embora não se tenha comparado diferentes técnicas operatórias, a colpotomia se mostrou rápida, o cirurgião rapidamente adquiriu prática e não foi observado grande desconforto ao animal ou ao cirurgião. A via vaginal teve ainda como vantagem a rápida cicatrização, não requereu sutura e apresentou baixa incidência de complicações pós-operatórias.

Todos os sinais descritos ocorreram de forma independente, não havendo qualquer correlação entre a ocorrência de dor, ataxia e aderências ovarianas.

\section{CONCLUSÕES}

O protocolo anestésico e a técnica cirúrgica empregados mostraram-se seguros e eficientes na obtenção de fragmentos com tamanho adequado para uso em estudos da anatomia funcional luteínica envolvendo as técnicas histológicas-padrão, imunoistoquímica e de biologia molecular. A baixa incidência de aderências permite o uso consecutivo das fêmeas, sem interferência nas ovulações e colheitas subsequentes. Novos estudos são necessários para que se investigue a fertilidade futura desses animais.

\section{AGRADECIMENTOS}

À Fapesp, pelo suporte financeiro.

\section{REFERÊNCIAS}

CARON, J. P.; LEBLANC, P. H. Caudal epidural analgesia in cattle using xylazine. Canadian Journal of Veterinary Research, v. 53, p. 486-489, 1989.

CASSAR, C. A.; DOW, M. P. D.; PURSLEY, J. R.; SMITH, G. W. Effect of the preovulatory LH surge on bovine follicular progesterone receptor mRNA expression. Domestic Animal Endocrinology, v. 22 , p. $179-187,2002$.

CAULKETT, N.; CRIBB, P. H.; DUKE, T. Xylazine epidural analgesia for cesarean section in cattle. Canadian Veterinary Journal, v. 34, p. 674-676, 1993.

D'HAESELEER, M.; CORNILLIE, P.; SIMOENS, P.; VAN DEN BROECK, W. Localization of oestrogen receptors within various bovine ovarian cell types at different stages of the oestrous cycle. Anatomia, Histologia, Embryologia, v. 35, p. 334-342, 2006a.

D'HAESELEER, M.; COCQUYT, G.; VAN CRUCHTEN, S.; SIMOENS, P.; VAN DEN BROECK, W. Cell-specific localization of apoptosis in the bovine ovary at different stages of the oestrous cycle. Theriogenology, v. 65, p. 757-772, $2006 \mathrm{~b}$.

D'HAESELEER, M.; SIMOENS, P.; VAN DEN BROECK, W. Cell-specific localization of progesterone receptors in the bovine ovary at different stages of the oestrous cycle. Animal Reproduction Science, v. 98, p. 271-281, 2007.

DROST M.; SAVIO J. D.; BARROS C. M.; BADINGA L.; THATCHER W. W. Ovariectomy by colpotomy in cows. Journal of American Veterinary Medical Association, v. 200, p. 337-339, 1992.

HIRAOKA, M.; MIYAGAWA, T.; KOBAYASHI, H.; TAKAHASHI, T.; KISHI, H.; KOBAYASHI, H.; LEE, I. Sucessful introduction of modified dorsolumbar epidural anesthesia in a bovine referral center. Journal of Veterinary Science, v. 8, p. 181-184, 2007.

HOUGHTON, P. L.; LEMENAGER, R. P.; HENDRIX, K. S.; MOSS, G. E.; STEWART, T. S. Effects of body composition, pre and postpartum energy intake and stage of production on energy utilization by beef cows. Journal Animal Science, v. 68, p. 1447 1456, 1990.

IRELAND, J. J.; MURPHEE, R. L.; COULSON, P. B. Accuracy of predicting stages of bovine estrous cycle by Gross appearance of the corpus luteum. Journal of Dairy Science, v. 63, p. 155$160,1980$. 
JO, M.; KOMAR, C. M.; FORTUNE, J. E. Gonadotropin surge induces two separate increases in messenger RNA for progesterone receptor in bovine preovulatory follicles. Biology of Reproduction, v. 67, p. 1981-1988, 2002.

KLIEM, H.; BERISHA, B.; MEYER, H. H. D.; SCHAMS, D. Regulatory changes of apoptotic factors in the bovine corpus luteum after induced luteolysis. Molecular, Reproduction and Development, v. 76, p. 220-230, 2008.

KOT, T.; ANDERSON, L.; TSAI, S.; WILTBANK, M.; GINTHER, O. Transvaginal ultrasound-guided biopsy of the corpus luteum. Theriogenology, v. 52, p. 987-993, 1999.

LEE, I.; YAMAGISHI, N.; OBOSHI, K.; AYUKAWA, Y.; SASAKI, N.; YAMADA, H. Comparison of xylazine, lidocaine and the two drugs combined for modified dorsolumbar epidural anaesthesia in cattle. Veterinary Record, v. 155, p. 797-799, 2004.

SILVA, L. A. F.; ALMEIDA, C. F.; VIANA FILHO, P. R. L.; VERÍSSIMO, A. C. C.; RABELO, R. E.; EURIDES, D.; FIORAVAN-
TI, M. C. S. Descrição de duas técnicas cirúrgicas para castração de fêmeas bovinas e avaliação do pós-operatório. Ciência Animal Brasileira, v. 5, p. 47-53, 2004.

ST JEAN, G.; SKARDA, R. T.; MUIR, W. W.; HOFFSIS, G. F. Caudal epidural analgesia induced by xylazine administration in cows. American Journal of Veterinary Research, v. 51, p. 1232-1236, 1990.

VAN DEN BROECK, W.; D'HAESELEER, M.; CORYN, M.; SIMOENS, P. Cell-specific distribution of progesterone receptors in the bovine ovary. Reproduction in Domestic Animals, v. 37 , p. 164-170, 2002a.

VAN DEN BROECK, W.; CORYN, M.; SIMOENS, P.; LAUWERS, H. Cell-specific distribution of oestrogen receptoralpha in the bovine ovary. Reproduction in Domestic Animals, v. 37, p. 291-293, 2002 b.

Protocolado em: 25 ago. 2009. Aceito em: 17 mar. 2010. 